\title{
Archives 101: Engaging Post-Secondary Students with Primary Sources
}

Emily Lonie and Ashleigh Androsoff

\begin{abstract}
This article documents a productive partnership between a local archives and a community college that resulted in an enhanced learning experience for students and provided an opportunity to connect the archives with an underserved audience. Students were asked to creatively commemorate the life of a soldier or nurse who served in the First World War using archival military service files as inspiration. Through the project, students developed their research and communication skills and became familiar with the functions of an archives and the utility of working with primary source documents. The project successfully blended archival research with a creative pedagogical approach and serves as a model that could be adapted to fit a diverse range of subjects, using a variety of archival collections.
\end{abstract}

The Lest We Forget Project was conceived in 2001 by Blake Seward, a history teacher in Smith Falls, Ontario, who felt that the contributions of the men and women who served in the First World War were being forgotten. He observed that it was increasingly difficult for twenty-first century students to empathize with the people who had enlisted in Canada's war effort nearly one hundred years earlier. He began researching his own relatives using the military service files held by Library and Archives Canada (LAC), and soon realized that this research approach, which provides an opportunity to engage with primary source documents, could help to forge a real connection between his students and the past. What better way to learn about Canada's involvement in the First World War, than by physically experiencing the records of the soldiers and nurses who participated in it?

Seward took his class to Ottawa, where they consulted military service files at LAC. Students each researched a soldier whose service is commemorated at the Smiths Falls cenotaph and produced a short essay about the individual's wartime experience. The students compiled significant information about their local soldiers and created a virtual museum display featuring the lives of more than one hundred local soldiers and nurses. ${ }^{1}$

Library and Archives Canada recognized the value in this project and expanded it. Workshops were held in Ottawa with local high school classes and were soon combined with a visit to the Canadian War Museum. This partnership enhanced the visceral experience for the students, who were able to physically consult original service files while experiencing the related artifacts in the museum. LAC's ongoing digitization of the 640,000 military service files in its holdings expanded the accessibility of these archival records to remote researchers, thereby facilitating a national expansion of the Lest We Forget Project. At its height, the project was delivered in partnership with public libraries in British Columbia, Ontario, Manitoba, Nova Scotia, and Alberta.

\footnotetext{
1 "Lest We Forget." Virtual Museum of Canada. Canadian Museum of History. Web. 12 September 2016. (http://www.virtualmuseum.ca/sgc-cms/histoires de chez nouscommunity memories/pm v2.php?id=exhibit home\&lg=english\&ex=00000476)
} 


\section{A Productive Partnership}

The City of Coquitlam Archives was founded in 2013. As the first City Archivist, Emily Lonie was committed to raising awareness about the new service and encouraging the use of archival records through a range of outreach initiatives aimed at various audiences. Having previously worked as an archivist at Library and Archives Canada, Lonie was aware of the Lest We Forget Project, but had never been directly involved. She believed the project could offer a useful introduction to working with archival materials and would present an opportunity to connect with an underserved local audience. In 2014, she reached out to Dr. Ashleigh Androsoff to determine if the project would be a good fit for Canadian history courses at Douglas College. Androsoff greeted the proposal with much enthusiasm and agreed to assign it as part of the "Canada after Confederation" survey course.

The partnership with Douglas College was in keeping with the City Archives' public outreach mandate, as it provided an opportunity to introduce archival records to students who normally might not be exposed to working with primary sources until much later in their academic careers. The project also offered an opportunity to guide Douglas College history students through a hands-on demonstration of how historical material is preserved, disseminated, interpreted, and ultimately presented to the public. Together, Lonie and Androsoff developed a project that took inspiration from Seward's original concept, but enhanced the research requirements and project deliverables to suit students at the undergraduate level. Since the creative output of the assignment required students to create a commemoration of a soldier or nurse's service, launching the project in the fall term of 2014 seemed particularly fitting because it would align with the centennial of the First World War.

The project was introduced to students during a regular three-hour class, starting with Androsoff's lecture on Canada's involvement in the First World War. Lonie then provided a guest lecture that focused on the societal role of archives and the power of primary sources. The desire was to convey passion and enthusiasm for archival records in order to excite the students as they prepared to conduct their own primary source research. The lecture concluded with an explanation of the historical context of wartime recordkeeping and a detailed breakdown of the contents of a military service file.

When introducing the assignment, Androsoff defined "commemoration" and "public history," outlined ethical considerations students might keep in mind when commemorating a First World War soldier or nurse, and provided a list of academic and creative elements that were required in the final product. Students were asked to use the historical insights gleaned from the lecture and scholarly secondary sources to interpret the archival records. Using the historical information as inspiration, they were to create a commemoration of a soldier or nurse. Students were permitted to use creative license to fill in any gaps in the archival record, so long as the creative elements were consistent with what is known about the Great War experience. The students were expected to provide comprehensive referencing to indicate the source of their information and to explain any fictional embellishments.

The Lest We Forget Project encouraged students to make a personal connection with the material, by getting to know one soldier or nurse through his or her documentary record, and 
then putting that particular service person into the broader historical context. If the soldier's record indicated that he was hospitalized with sepsis after Vimy Ridge, for example, the student could use what he or she learned from the secondary source material to try to imagine what that soldier's experience in the battle or in the hospital might have been.

Students were encouraged to be creative in selecting a format for their commemoration: they could submit creative writing, audio-visual compositions, museum displays, websites, or fine art productions such as paintings, drawings, or sculptures. Students were limited only by their imaginations. They were assured that while a pleasing aesthetic was desirable, they were being evaluated on the overall intelligence and effect of the presentation, rather than on their technical or artistic skills.

The learning outcomes for the project extended beyond reconstructing the experiences of particular veterans and beyond understanding Canada's participation in the First World War. Students were introduced to the archival research process, including the consultation of finding aids, online catalogues, and databases. They also learned that often relatively little is known about individuals' experiences of the past, and it can be difficult to recreate those experiences with only a few documents to depend on. One of the project's objectives was to demonstrate to students how exciting - and sometimes frustrating - archival research can be. They learned about the thrill of finding "the missing piece," and in some cases, they got a taste of the frustration of being unable to read it, either because of obscure handwriting, deterioration of the document, or poor reproduction quality. Since students were encouraged to think about how to interpret past events and present them to others, they were also able to consider what goes into the production of creative representations of the past such as period films or historical fiction, and gained insight into the production of public history exhibitions such as museum installations or memorials.

When first introduced to the project, some students exhibited a mixture of skepticism and fear. The project deviated from the standard research paper or midterm exam they had come to expect in university history courses, and this created some initial anxiety. The in-class archival presentation and online handouts went a long way towards demystifying archival research and gave students confidence about locating and interpreting primary sources.

After completing the assignment, many students indicated, both in casual comments and in formal course evaluations, that they loved doing the project and had connected with the history of the First World War in a far more personal way than they had anticipated. Most students submitted their assignments with considerable pride and their submissions demonstrated high levels of engagement with the material. In most cases, it was clear that students undertook additional research in an effort to do justice to the memory of the soldier or nurse. Most students were quite thoughtful about how to convey the results of their research in a publicly-accessible format that was both emotive and informative.

In the first incarnation of the project, many students selected the same soldier. The reasons for doing so were unclear. Was it ease of access? Was he the first soldier they came across in the database? Did they like something particular about the story? Curious about what motivated students to select a specific soldier or nurse, and wanting to emphasize the point that their selection should be deliberate, the project deliverables were amended to require a short 
explanation of why the particular service person was selected. Once this requirement was in place, a broader diversity of individuals appeared in student submissions. Some students explained in their rationale that they were looking for a particular type of person: for example, some students wanted to profile a soldier whose record indicated he had been injured in action; others wanted to focus on a soldier from a particular ethnic group.

It appeared that requiring students to explain their selection prompted them to make a more meaningful connection with the subject matter. For example, one student reported that reading the war diaries for his soldier's battalion helped him "get a feel for what it is that historians do." He explained that, as he continued to review the primary source documents in his soldier's digitized service file, "a picture began to form and what was once a single name among thousands of service files was now starting to take flesh."2 Another student expressed shock that her soldier was the same age as she was, and yet he had sacrificed his life. He never experienced marriage nor had children, two things she desires in her life. Requiring students to explain their choices highlighted the degree to which students were empathizing with the soldiers or nurses they had selected.

\section{Publicizing the Project Results}

When students submit research essays or exams, their audience is usually limited to the instructors who mark their work, and perhaps a selection of close friends and family members. The Lest We Forget Project differs from conventional history assignments by making public access to the student's work - in theory, if not also in practice - a central component of the project design. Students were required to showcase their work in class. In order to celebrate the students' achievements and set them up for success for their next creative project, Androsoff highlighted projects that stood out for the quality of the research or the intelligence of the creative design.

Students were informed from the outset of the possibility that their work would be publicly exhibited. This motivated the students to submit their best work, and reified the public history dimensions of the project. Though many excellent projects were submitted, five projects met the criteria for public display. These projects stood out both intellectually and aesthetically. The students who created them explicitly used data from their soldier's digitized service file, as well as data collected from extensive background research, to create an eye-catching and thoughtprovoking commemorative piece.

One student's commemorative box was featured in the City of Coquitlam Archives' Annual Report for 2014, while others were displayed at the Coquitlam Public Library as part of two Lest We Forget exhibits curated by Emily Lonie in 2015 and 2016. Taking advantage of public interest in First World War commemoration activities, the local media was alerted to the partnership between the City of Coquitlam Archives and Douglas College. The students' work was featured in local newspapers, radio and television broadcasts, and social media.

\footnotetext{
${ }^{2}$ Kyle Tillotson, "Lest We Forget: Rationale" (coursework, submitted for HIST1114 "Canada After Confederation," Department of History, Douglas College, New Westminster [B.C.], 2 March 2016).
} 
Publicizing the students' work fulfilled two of the Lest We Forget Project's main objectives. First, it ensured that the Canadian soldiers and nurses who served in the First World War are not forgotten. Second, it gave the students an opportunity to apply what they learned about public history beyond the limits of the classroom. Publicizing the Douglas College partnership also highlighted the City of Coquitlam Archives' outreach initiatives and demonstrated that the Archives is an active participant in the City's public discourse. It also highlighted Douglas College's efforts to offer a unique approach to post-secondary education: one that emphasizes a hands-on and more personalized learning experience in a community-engaged and localized environment.
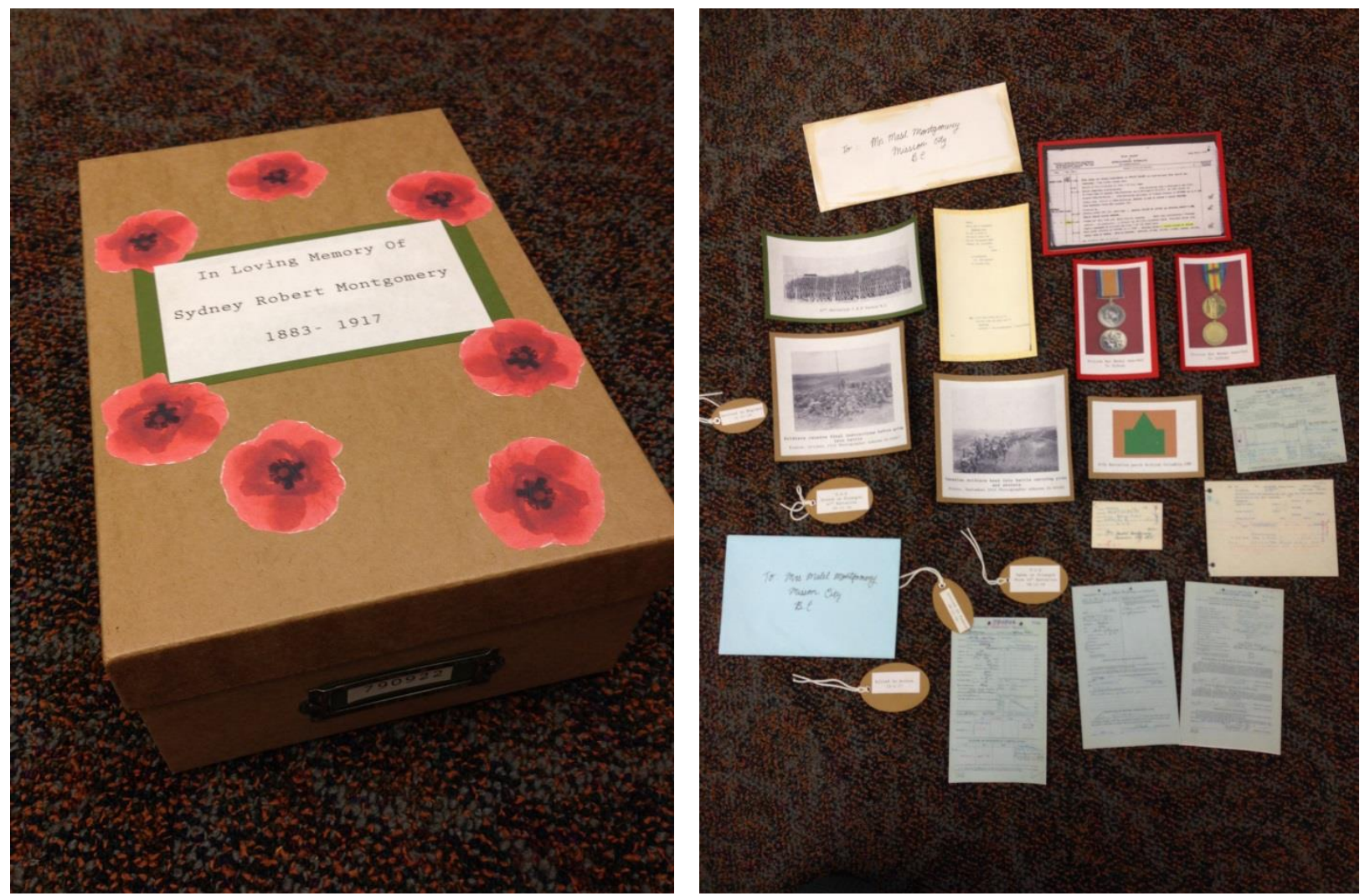

Commemorative Box - Sydney Robert Montgomery, created by Emma McCracken, November 2014.

(Photographs by Ashleigh Androsoff) 


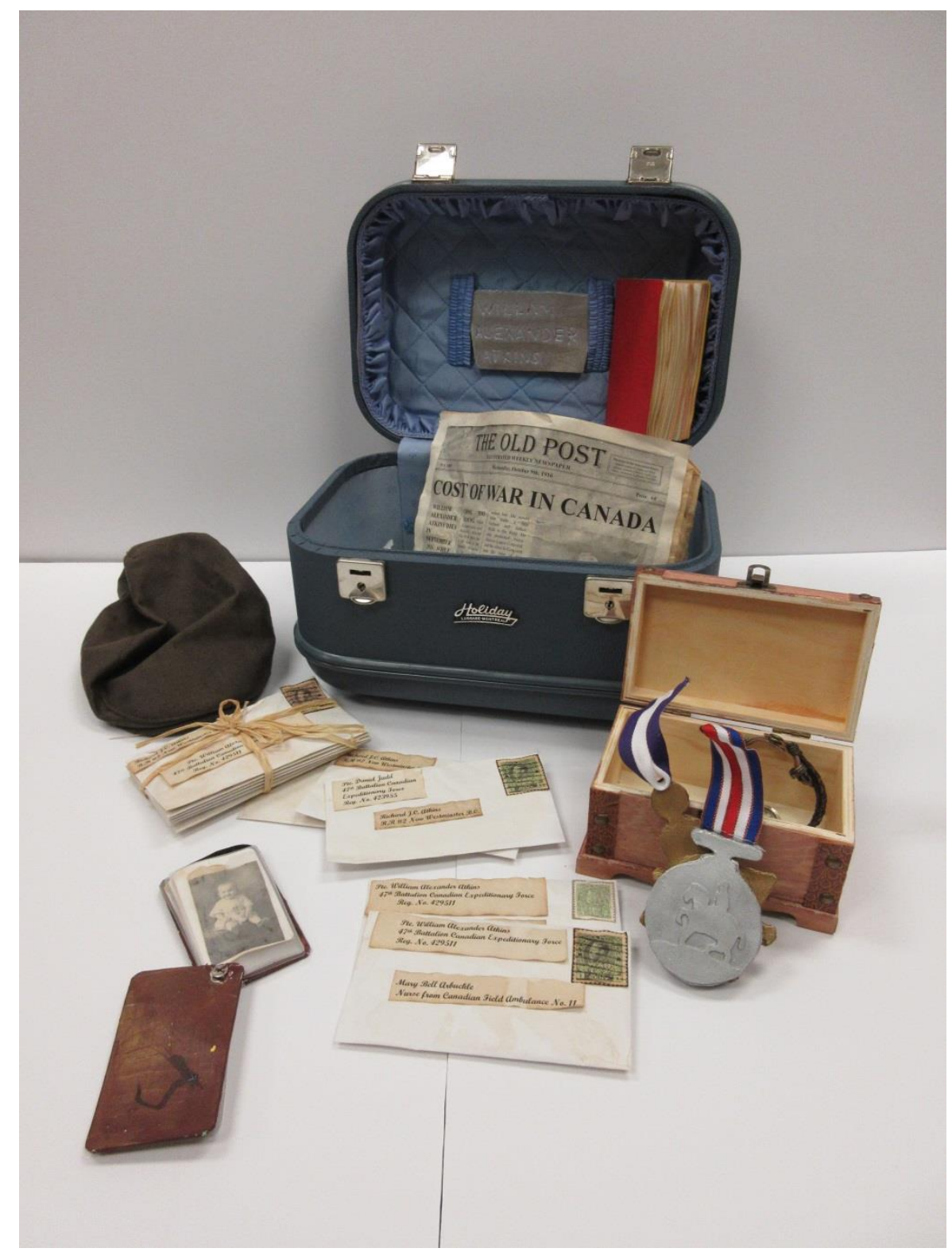

Imagined Suitcase belonging to William Alexander Atkins, created by Vanessa Stewart, February 2015.

(Photograph by Emily Lonie) 


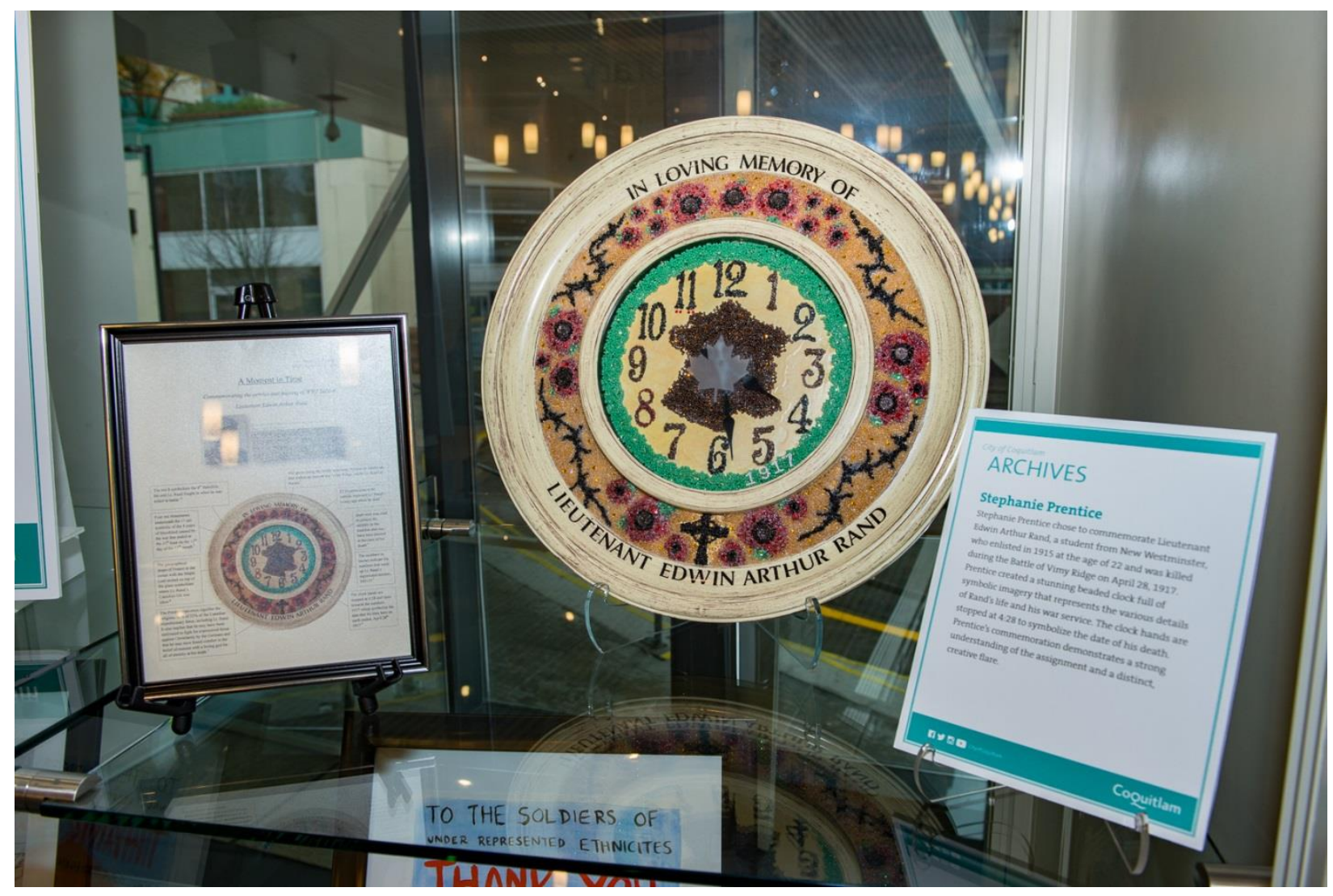

A Moment In Time, created by Stephanie Prentice, 2016.

Shown here as part of the 2016 Lest We Forget Exhibit, curated by Emily Lonie.

(Photograph by Ron Kozlowski) 


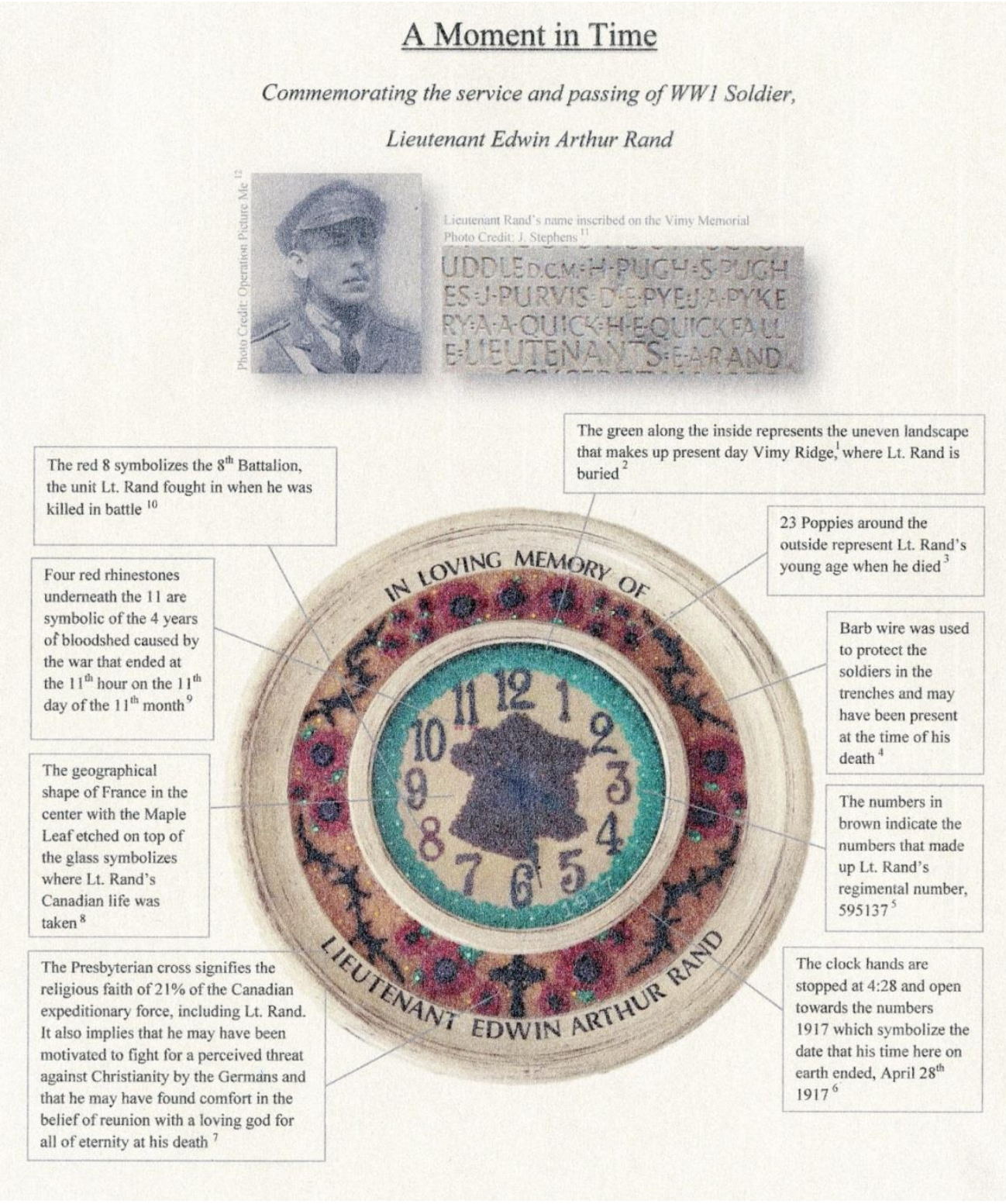

Explanation of the symbolic elements in A Moment in Time, by Stephanie Prentice, February 2016 


\section{Conclusion}

The Lest We Forget Project integrated archival research and creative pedagogy to generate a high quality learning experience for undergraduate students. Lonie and Androsoff adapted Blake Seward's vision to suit a more advanced audience, and thanks to LAC's commitment to preservation and digital access, were able to offer students the opportunity to learn directly from primary source material. While consulting a digital surrogate cannot replace the experience of working with an original archival document, students were still able to reach into the past to make a meaningful connection with the chosen service person and bring his or her memory to life.

Students learned to follow the story from the archival record through to the secondary sources, to interpret what they discovered, and to produce a creative commemoration. This is a model that could be easily adapted to fit with a diverse range of subjects, using any number of archival collections. It provides educators and archivists opportunities for enriching and productive collaboration and encourages students to connect intellectually and emotionally with the material, thereby making archives relevant to a new generation. 